Discussion Paper Series No.169

Intellectual Property Rights Protection and Imitation

--- An empirical examination of Japanese FDI in China ---

\author{
Kegang You Kobe University \\ Seiichi Katayama Kobe University
}

April 2005

Discussion papers are a series of manuscripts in their draft form. They are not intended for circulation or distribution except as indicated by the author. For that reason Discussion Papers may not be quoted, reproduced or distributed without the written consent of the author. 


\title{
Intellectual Property Rights Protection and Imitation --- An empirical examination of Japanese FDI in China ---
}

\author{
Kegang You ${ }^{1}$ \\ Seiichi Katayama ${ }^{2}$ \\ 2003/2 the first version \\ 2005/3 the second version
}

\begin{abstract}
By using the data obtained from a questionnaire survey to the Japanese firms in China this paper empirically examines the effects of the IPRs protection against local illegal imitation. No evidence has been found in the test that the patent and trademark registration, which constitutes a part of the whole IPRs protection system, has protective effect. To the contrary the results suggest that the patent and trademark registration system may play a role in facilitating local illegal imitation and may be mediate technology transfer/diffusion in China.
\end{abstract}

Keywords: IPR, Patent, Imitation, technology diffusion, FDI

JEL Classification: O34, O38

\section{Introduction}

Since the end of 80's, Intellectual Property Rights protection (IPRs) has become a

prominent issue on the strategies of countries, especially in terms of foreign direct investment (FDI).

Later during 1994 to 1995, the introduction of TRIPs in GATT and the afterward WTO pushed this

worldwide IPRs protection to a high tide. Such a campaign on IPRs protection reflects the following

two features of the present market competition. First, the growing capacity of traditional

Corresponding author: Seiichi Katayama: Tel \& Fax: \#81-78-803-7012, E-mail: katayama@rieb.kobe-u.ac.jp

1 Faculty of Business Administration, Kobe University

2 Research Institute for Economics and Business Administration, Kobe University. 
manufactures in developing countries has forced developed countries to rely more heavily on their comparative advantages in production of intellectual goods. Second, not only the cost of R\&D is often disproportionately higher than in the past, but the resulting innovation embodied in today's high-tech products has increasingly become more vulnerable to free-riding imitators.

Due to this kind of global pressure, strengthening IPRs protection in developing countries has become an unavoidable tendency in order to attract more FDI, to access to better technologies and ultimately to attain higher economic growth.

A straightforward reason why strengthening IPRs protection could raise FDI is expected as its power on reducing local illegal imitation, consequently reduces a risk of FDI and ensures the profits of investors. And a preparation of such a TRIPS standardized system is made use of as (1) a symbol of improvement of FDI environment in developing countries; (2) a powerful card at the WTO negotiation for both developed and developing countries. The campaign of IPRs protection has been occurred over a decade, however the situation of illegal imitation in developing countries has not improved considerably. For example, the Japanese Patent Office Annual Investigation Reporter on the issue of the infringement on Japanese firms' IPRs shows that the situation is deteriorating year after year ${ }^{3}$. This raises a question as to whether the IPRs protection in developing countries has the effect of reducing the local illegal imitation or not. An analysis of this question would provide some

\footnotetext{
${ }^{3}$ Visit http://www.jpo.go.jp/index.html for further information.
} 
useful policy implications for the IPRs protection in WTO. First, we can clarify the performance of the IPRs protection in developing countries. Second, if the IPRs protection in those countries does not perform effectively, it will help to construct an ideal architecture of IPR protection. Consequently it will lead us to consider what a new mode of WTO negotiation, which contributes to the world trade and FDI, should be.

To the authors' knowledge, not many researches have been done in the past literatures.

There are some papers studying the relations among IPRs protection and FDI, trade and economic growth, etc ${ }^{4}$. In spite of the intense debates concerning the relation between IPRs protection and FDI since the Uruguay Round, no settled result has been found both empirically and theoretically and those results, no matter what they are, may provide some kind of misapprehensions on this issue ${ }^{5}$. That is, although many of them argue that IPRs protection is effective for reducing illegal imitation, the direct causality has not been demonstrated. Therefore, based on the result that IPRs may (or may

\footnotetext{
${ }^{4}$ Chin \& Grossman (1990) and Deardorff (1992) examine welfare effects of the extending IPRs protection from the developed countries to developing countries. They find that in most of the cases strengthening IPRs protection in developing will lower the welfare level. Gould \& Gruben (1996) examines empirically the role of IPRs protection in economic growth, utilizing cross-country data on patent protection, trade regime and country-specific characteristics. Their evidence suggests that IPRs protection is a significant determinant of economic growth. Evidences from Maskus \& Penubarti (1995) show how IPRs protection is trade-related. And Vishwasrao (1994) shows that the lack of IPRs in developing countries can affect the mode of technology transfer from the developed countries.

5 Among empirical studies, Ferrantino (1993), by using US's FDI data, found that there is at most a weak association between countries' decisions to join IPRs protection agreements and their decision to pursue “ open” policies with regard to trade or FDI. Kondo (1995) found that there is no evidence supporting that FDI is affected by patent protection, by using data on US. Outward FDI. However, Seyoum (1996), based on a study of 27 countries' inflows of FDI, showed that the level of IPRs protection is a strong determinant of inward FDI. And Lee \& Mansfield (1996), by using their random sampling data of 100 major U.S. firms in six manufacturing industries, found that the outward FDIs of those 100 major U.S. manufactures are strongly related to the level of IPRs protection of host countries. Among the theoretical studies, Helpman(1993) shows that strengthening IPRs in developing countries will lower the inflow of FDI from these developed countries, by using a dynamic model. On the contrary, Lai(1998) shows the opposite.
} 
not) boost FDI, we can not confidently assert that IPRs protection may (or may not) reduce illegal imitation. Hence this paper is trying to provide some empirical evidence on the relation between IPRs protection and illegal imitation.

Our procedure is based on a survey of the Japanese firms having direct investment in China. China has become a largest FDI host country among all developing countries led by her opening economic policy. Ever since then Japan has been ranked the second largest FDI sourcing country to China among the OECD countries after the U.S.

Although China has legally established a series of IPRs protection systems (she is a member of Paris Convention, WIPO), the present circumstances on IPRs protection policy in China is severely criticized. For example, the above-mentioned Japanese Patent Office Annual Investigation Report states that in 1999 about 27\% of the total imitations of Japanese products in the world are observed in China. And now China has passed her first year as a member of WTO. Considering all we focus on China for finding some empirical facts.

To investigate a possible relation between the IPRs protection and illegal imitation, two control variables are selected. One is a five point scaled index marked by our survey respondents in evaluating the total condition of the IPRs protection system in China. The other is a dummy variable with its value of 1 implying that the products of the firm of the survey respondent have been patented or trademark-registered. By using this dummy variable, the effects of a certain part of the 
total IPRs protection system in China can be verified. The reason of choosing it is obvious since, among a set of IPRs protection measures, the patent and trademark-registration system is expected to be most effective. As a result, our test robustly shows an interesting fact that the patent and trademark-registration system in China does not perform well. Therefore it is suspected that the system is facilitating local illegal imitation and could be mediating technology transfer/diffusion in China. This result supports the Japanese firms' perception, and suggests the necessity to reconsider the better IPRs protection system. The relations among profit, IPRs protection and illegal imitation are also examined in this paper.

The constructions of the paper are as follows. In section II we present some descriptive data and a theoretical consideration for the empirical study of the effects of patent and trademark-registration system to reduce local illegal imitation. The empirical results are shown in section III, and in section VI we study the relation among profits, imitation and IPRs protection. Concluding remarks are stated in the final section.

\section{Data and Estimation Issues}

II-1 The data description

According to a data-base, which is provided by TOYOKEIZAI SHINPOSHA ${ }^{6}$, of Japanese firms investing in China 2000 we randomly sampled 412 source firms and sent our

6 Toyokeizai Shinposha is a major data source bank in Japan which provides firm level data. Visit http://www.toyokeizai.co.jp for further information about it. 
questionnaire to their presidents. The answering period was set from $15^{\text {th }}$ July to the end of August, 2001. Among them 98 answers have been returned and the reply rate is $23.8 \%$. From those answers we obtained their 228 subsidiaries' data in 7 manufacturing industries: Glass, Fiber, Vehicle, Food, Chemistry, Machine and Electronics. Among them 188 data are distributed in 13 cities that accepted Japanese FDI. They are Peking, Shanghai, Tianjing, Shenyang, Dalian, Qindao, Suzhou, Guangzhou, Shenzhen, Dongguan, Zhuhai, Xiamen and Fuzhou.

In the questionnaire we set a series of questions including the location, the category of industry, the investment share with their partners, the amount of investment and the number of years of the establishment of their subsidiaries, etc. Also we asked them whether products with the same category of the products of their subsidiaries are imported to China from Japan or other countries; and whether or not local firms are producing products with the same category of the products of their subsidiaries. Concerning the IPRs protection, we asked them whether or not the products of their subsidiaries have been illegally imitated by local firms, and whether or not there are imitated products with the same category of the products of their subsidiaries imported to China from other countries. Further we asked them whether the expected profits of their subsidiaries have been realized, and in the case when it has not been realized we asked them whether imitation is one of the major factors to make their subsidiaries unprofitable. Further, we asked them whether the products of their subsidiaries have been patented or registered for trademark. Finally we asked them to 
evaluate the level of IPRs protection at the location of their subsidiaries by using a five point Ricard Scale method, with the point 5 designates that the legal enforcement of IPRs protection in that location is top ranked.

******* Table 1 and 2 are about here

Some of the data obtained from our questionnaire are shown in Table 1, and the meanings

of all elements in Table 1 are stated in Table 2. The Data in Table 1 provide some basic information of the Japanese FDI in China in terms of IPRs protection. Firstly, the level of the IPRs protection in China was marked on average at 2.60 point, which implies that the actual effectiveness of IPRs protection in China is not good enough in comparison with China's IPRs protection system as a legislatively complete architecture. Secondly, on average about $62 \%$ of the Japanese subsidiaries answered that their products have been patented or registered for trademark. This means that the Japanese subsidiaries in China are relatively sensitive to the protection of their products. Thirdly, Table 1 shows that on average nearly 30\% of the products of the Japanese subsidiaries have been imitated. The other information from Table 1 is that on average $57 \%$ of the products of Japanese subsidiaries have their competitors in Japan, 36\% of the products of Japanese subsidiaries have their competitors in other countries, and nearly $70 \%$ of the products of Japanese subsidiaries have their competitors in China. And on average about $47 \%$ Japanese subsidiaries have not realized their expected profits. 
A correlation matrix for all elements in Table 1 shown in Table 3 suggests the direction of our empirical study. That is, the correlation between patent and trademark-registration system and imitation tends to be positive, which is in contradiction to our normal expectation. In order to study whether this positive correlation is economically meaningful, we go on to the following regression tests.

II-2. A basic consideration for the empirical study

For the empirical study, we consider first some features of imitation. Among the existing literatures, imitation is treated as a costless activity for simplicity. However, in the real world, it is considered to be a costly activity which is similar to R\&D activity except that the aim is not to develop new products but to imitate certain existing products. Here we follow Grossman and Helpman (1991)'s type of a formulation of product imitation function in which the imitation is treated as a type of innovation production function.

$$
n^{s}=f\left(n^{m}, L^{I}\right), \partial n^{s} / \partial n^{m}>0, \partial n^{s} / \partial L^{I}>0 .
$$

In the equation (1), $n^{s}$ is the number of fruit of imitation; $n^{m}$ represents the existing number of Multinational Enterprises (MNE) goods which is considered as a proxy for the volume of information available for imitation; and $L^{I}$ represents resources invested for the imitation 
activities.

It is expected that the IPRs protection could reduce the accessible number of MNE goods for imitation. Let $p$ denote the ratio of the number of MNE goods patented or trademark-registered to the total number of whole MNE goods. Hence $n^{m}=h(p), \partial n^{m} / \partial p<0$.

The fruit of imitation is considered as a function of resources invested for information which is affected by such basic factors as the spirit of law observance, legislation system and administration of justice. We consider such factors as a notion of IPRs protection, and denotes this aggregated evaluation of the broad IPRs protection as $\omega$. And suppose that the higher $\omega$ i s, the more reduction on the invested resources for imitation is realized. $L^{I}=g(\omega), \partial L^{I} / \partial \omega<0$.

Taking it into consideration that imitation is trade-related, we add trade variable $T$, and in order to reflect how local productivities influence local imitation, we add a variable $L P$ expressing the local production information into the equation (1). Then the imitation production function can be expressed as follows.

$$
n^{s}=f(\omega, p, T, L P),
$$

where $\partial n^{s} / \partial \omega<0, \partial n^{s} / \partial p<0, \partial n^{s} / \partial T>0, \partial n^{s} / \partial L P>0$ are expected.

II-3. The specification and some issues for the estimation 
By adding the subscripts representing each subsidiary of an industry in a certain city to the variables in equation (2), we specify it into the structural equation (3) by which our Probit test is conducted.

$$
\begin{aligned}
I M I_{j k i} & =\alpha_{0}+\alpha_{1} L_{E V E L_{j}}+\alpha_{2} P_{A T}+\alpha_{3} T_{R A D 1_{j}}+\alpha_{4} T_{R A D E 2_{j}}+\alpha_{5} L O C A L_{j} \\
& +\beta_{i} \text { CITY }_{i}+\gamma_{k} I N D_{k}+e_{j i k}
\end{aligned}
$$

In the equation (3), $I M I_{j k i}$ represents a dummy variable of a Japanese subsidiary $j$ of industry $k$ in city $i$, with its value of 1 expresses that this subsidiary answered that her products have been imitated and zero otherwise; $L E V E L_{j}$ represents the evaluation point of the IPRs protection of a certain city marked by subsidiary $j ; P A T_{j}$ represents a dummy variable of subsidiary $j$, with its value of 1 means that this subsidiary reported that her products have been patented or registered for trademark; $T R A D 1_{j}$ represents a dummy variable of subsidiary $j$, with its value of 1 means that this subsidiary reported that some products with the same category of her product have been imported to China from Japan, and zero otherwise ; $T R A D 2_{j}$ represents a dummy variable of subsidiary $j$, with its value of 1 means that this subsidiary reported that some products with the same category of her product have been imported to China from other countries, and zero otherwise ; $L O C A L_{j}$ represents a dummy variable of subsidiary $j$, with its value of 1 means that this subsidiary reported that the local firms are producing products with the same category of her product, 
and zero otherwise ; and $C I T Y_{i}$ is a city dummy and $I N D_{k}$ is an industry dummy. The last two

control variables are added in order to observe some local and industrial characteristics.

The first issue of the estimation is errors in variable. In the equation (2) $\omega$ is an exogenous variable for the proxy of legal system and law observance. When we apply the LEVEL from the sampling data to this variable $\omega$, it is strongly suspected that the dependent variable $I M I$ and the explanatory variable $L E V E L$ are highly correlated. Because, when a sample observes an imitation, the evaluation of the legal system and low observance, LEVEL, could be identified to be low. Actually this suspicion is turned to be correct ${ }^{7}$. Hence we delete $L E V E L$ as a control variable. And we regress $P A T$ to $I M I$. However, as a second step we use the $L E V E L$ as an instrumental variable for $P A T$ since $L E V E L$ and $P A T$ causes endogeneity bias in the sense that the firm's choice between patents or not depends on LEVEL. When we use the IV estimation, we could avoid two problems ${ }^{8}$. One is an endogeneity bias arising from the variable PAT which could be endogenous in the sense that firm chooses patents or not and, the other is

7 The vector of $I M I$ consists of an element of the set $[0,1]$ and, that of $I P R L$ consists of a positive integer of the set $[1,2,3,4,5]$. Both IMI and IPRL are in non parametric space in the sense that the two variables are not continuous type. Hence we did not take a simple correlation coefficient of these variables. Instead we consider the alternative way to check a probabilistic character of the distribution of these two variables. And we can identify that it is highly probable that these two variables are drawn from different populations. This means that the population that replied to be imitated and the population that replied not to be imitated are expected to be different. Accordingly the whole populations of IPRL are considered to consist of two different groups of samples. This implies that $I M I$ and $I P R L$ are highly correlated.

The statistical evidence is as follows. There are two sample distributions, A and B. A is a sample distribution that consists of the evaluation points of the firms which answered being imitated. $B$ is a sample distribution of the points which answered not being imitated. We conducted two tests of equivalence of means of the sample distribution $A$ and $B$ under equal and unequal variance. Under unequal variance assumption $A \sim N(2.42,1.02)$ and $B \sim N(2.83,0.95) t=-2.51$ and under equal variance assumption $A \sim N(2.42,1.02)$ and $B \sim N(2.83,0.95) t=-2.56$. With $95 \%$ confidence level the null hypothesis of equivalence of the sample means of $A$ and $B$ is declined.

8 See, for example, chapter 8 of Wooldridge (2002). 
the simultaneous bias arising from IMI and PAT which means that either the former could be a dependent variable of the latter or the vice versa. To avoid the simultaneous bias a possible alternative IV for $P A T$ is $P A T(-j)$ which is constructed in such a way that each element is the ratio of the other firms patented to the whole firms in the same industry and/or city.

To test the robustness of the correlation between $I M I$ and $P A T$ we conducted these three different estimations.

\section{The Empirical Results on IPRS Protection and Imitation}

The Probit test results are shown in Table 4. The coefficient of patent and trademark-registration system shows a positive sign and is statistically significant, and this is consistent with the correlation derived in Table 3. The result may be beyond our normal expectation.

One possible explanation of this result is that, the social recognition on patent and trademark-registration system in China is so low that the system could not work effectively. Contrary to a normal sense, the actual patent and trademark-registration system could be playing a role of facilitating local imitation and, as a result, there is technology transfer / diffusion through the channel. Note that patent applicant is required to submit the appropriate technical details for registering patent. A patented or trademark-registered product may be regarded as profitable, so it could be targeted for imitation in an environment with the weak social recognition on IPRs. This is also supported by the estimation result of the profitability and patent in the next section. In this 
sense, a product with patent and trademark registration could be a fascinating target for imitation.

$* * * * * * * *$ Table 4 is about here $* * * * * * *$

In the subset 2, we have an additional variable, trade with Japan to control international

effects. The result of the patent and trademark-registration system is the same as those in the subset

1.

In the subset 3, we also add another trade- related variable which is trade with other countries than Japan. The result of the patent and trademark-registration system is also consistent with what we obtained in the first two subsets. And the coefficient of the existence of trade flow from other countries is positive and statistically significant. However, in this case the coefficient of trade from Japan tends not to be statistically significant. This implies that imitation is trade-related.

To avoid the possible correlation between the variables of trade flow from Japan and other countries, in the subset 4 instead of using $T R A D 1_{j}$ and $T R A D 2_{j}$, we added a new dummy variable, $T R A D 12_{j}$, with its value of 1 means that this subsidiary answered that the products with the same category of her product have been imported to China both from Japan and other countries, and zero otherwise. As a result, the test of the subset 4 shows that the sign of the coefficients of the patent and trademark-registration system is consistent with the result in the first three subsets.

On the subset 5, another control variable, local production, is added in order to test its influences on local imitation. The result shows a positive sign on it, however it is not statistically 
significant. The coefficients of other variables in this case are consistent with what we obtained in the previous subsets.

In the subset 6, dummy variables of city and industry are added in the test, (Guangzhou, Shenzhen, Dongguan and Zhuhai are integrated as one region of GU, and Xiamen and Fuzhou are integrated as a single region of XF), and there could not be found any meaningful evidence on these variables. However, the results of the coefficients of other variables are also consistent with all we obtained in other subsets. This suggests that the difference among cities is not significant.

It should be noted that in the estimates with IV it turned out that two instruments $L E V E L$ and $P A T(-j)$ were weak and hence it is not reported here.

\section{Profits, Imitation and IPRs Protection}

It is often asserted that local illegal imitation is a major cause for MNEs to be unprofitable, and IPRs protection will ensure MNFs to gain their expected profits. In this section we examine the relation among profitability, imitation and patents.

Our Probit test is conducted with the following equation.

$$
\begin{aligned}
\text { UNPROF }_{j k i} & =\lambda_{0}+\lambda_{1} \text { LEVEL }_{j}+\lambda_{2} \text { PAT }_{j}+\lambda_{3} I M I_{j}+\lambda_{4} T R A D 1_{j}+\lambda_{5} \text { TRADE2 }_{j} \\
& +\lambda_{6} \text { LOCAL }_{j}+\omega_{i} \text { CITY }_{i}+\sigma_{k} I N D_{k}+u_{j i k}
\end{aligned}
$$


In (4), $U N P R O F_{j k i}$ is a dummy variable of a subsidiary $j$ of industry $k$ in city $i$, with its value of 1 means that this subsidiary answered that her expected profits have not been realized, and zero otherwise. The meanings of the other variables are the same as in equation (3).

The independent variables of trade, $T R A D 1_{j}$ and $T R A D 2_{j}$, and local production are added in the test in order to control the relation between unprofitability and competition in the market. Later in the test, an independent variable $T R A D 12_{j}$, which represents the existence of trade flows both from Japan and from other countries, will be substituting the independent variables of $T R A D 1_{j}$ and $T R A D 2_{j}$. This is to avoid the possible correlation between the independent variables of trade flows from Japan and trade flows from other countries.

In the estimation equation (4) the control variables LEVEL, PAT and IMI could cause endogeneity bias. To avoid the endogeneity problem we conduct three different tests. Firstly, without using IV, we simply regress PAT and IMI to the dependent variable UNPROF. Secondly, we use LEVEL as an instrument for IMI. And thirdly, we use $P A T(-j)$ as an instrument for PAT.

Because of the statistically significant correlation between LEVEL and IMI, we first remove the dependent variable $L E V E L$ in equation (4), and test the influence of patent and imitation over firm's profitability. The results are shown in Table 5.

******** Table 5 is about here $* * * * * * * *$

The test of the subset 1 is a basic one. However, the coefficient of the independent variable 
of the patent and trademark-registration system is not statistically significant. In other words, there is no evidence from our data showing that the patent and trademark-registration system could have the effects of ensuring the profits of firms.

In the test of subset 2, two control variables of trade flows from Japan and trade flows from the other countries are added to investigate the influence of the intra-industry competition on the profits of firms. And the results show that the coefficients of this variables are positive but not statistically significant. Other results are consistent with what we observe in the subset 1 .

In the subset 3, two independent variables of trade flows from Japan and other countries and local production are added. As a result, the sign of the coefficient of trade flows from Japan and other countries is positive and statistically significant. This implies that foreign competition makes firms unprofitable. The result also suggests that there is no significant relation between local production and the profits of Japanese subsidiaries.

In subset 4, the dummy variables of both city and industry are added (Guangzhou, Shenzhen, Dongguan and Zhuhai are integrated as one region of Gu, and Xiamen and Fuzhou are integrated as on region of XF). Although there is no significant evidence for those dummy variables, the results concerning IPRs (including patent and trademark-registration system) are also consistent with the tests in previous subsets.

Then, we remove the independent variables of $L E V E L_{j}$ and $P A T_{j}$ in equation (7) to 
test the influence of the local imitation on the firm's profits. The results are shown in Table 6 .

****** Table 6 is about here $* * * * * *$

In Table 6, it is clearly shown that in all four subsets of the tests there has no statistically

significant evidence suggesting that local imitation makes the firms unprofitable.

As stated in the last section both the LEVEL as an instrument for IMI and PAT(-j) as an instrument for $P A T$ are weak instruments. Therefore the results of IV estimate is not stated.

The results in this section show the following facts. Firstly, there is no statistically significant evidence from the data showing that the patent and trademark-registration system, which is a part of the IPRs protection system, has the effects of ensuring the profits of Japanese subsidiaries. Secondly, the competition with the products imported from Japan and the other countries in the same category of the Japanese subsidiaries might be a significant factor making those Japanese subsidiaries unprofitable. Thirdly, there is no statistically significant evidence showing that the local production of the same category of the products of Japanese subsidiaries could influence the profits of those Japanese subsidiaries. This might suggest that the quality of local products has not yet reached to the level of those of Japanese subsidiaries, thus the local products could not be a threat to those products of Japanese subsidiaries.

\section{Concluding remarks}

In this paper we have studied the effect of IPRs protection system on local imitation and 
on the profitability of foreign subsidiaries by using the data obtained from our questionnaire on Japanese FDI in China.

One of the empirical observations indicates that the patent and trademark-registration system, which is a subsystem of the total IPRs protection system, does not necessarily work effectively in China. To the contrary, our results robustly suggest that such subsystem as patent and trademark registration could be providing a measure for local imitation and by this reason facilitating technology transfer/diffusion. For a product to be patented the detailed production information of the patented product is required to be open to the public. By utilizing those opened information the imitators could successfully imitate the product with relatively little resources. And at the same time the product registered for trademark is considered as a signal for profitability, and thus the risk of being imitated increases. The information becomes public after a fixed number of years when IPRs is rigorously enforced. However, the real situation is not so simple and it is a diplomatic argument between developed and developing countries and TRIPS in WTO.

There are many studies whether IPRs is a major determinant of FDI as the footnotes 4 and 5. From our empirical results there is no strong evidence to indicate that IPR is a significant determinant of FDI. The results in Table (5.) indicate that patents and imitation do not affect the profitability of the Chinese subsidiaries with a strong significance level. It is also suggested that not IPRs but rather the other factor such as market competition could be a significant factor in terms of 
profitability of FDI. The overall results suggest that further research is necessary to investigate the

links between FDI and IPRs.

\section{Acknowledgement}

We would like to thank for the comments by a referee, Jong Wha Lee, Gunther Schnabl, Eiichi Tomiura, Henry Ursprung, David Weinstein, Xingyuan Zhang, Junsok Yang, Kar Yiu Wong and the participants at the conferences of WTO and World Trade IV: Change in New Era at Gerhard-Mercator University in 2002 and Korea and the World Economy, III at Sungkyunkwan University in 2004. However the usual disclaimer applies.

This research is partly supported by the science fund of The International Center for the Study of East Asia Development, Kitakyushu (ICSEAD). The second author is grateful to the Ministry of Science and Education the 2002 research and DAAD at University of Konstanz. The part of this research was done while the second author was visiting at Columbia University, and he is grateful to the hospitality.

\section{References}

Chin Judith C. and Gene M. Grossman, 1990, "Intellectual Property Rights and North-South Trade “, in The Political Economy of International Trade: Essays in Honor of Robert E, Baldwin, ed. by Ronald W, Jones and Anne O. Krueger. Cambridge, MA: Basil Blackwell.

Deardorff Alan V., 1992, “Welfare Effects of Global Patent Protection”, Economica, Vol.59, 35-51.

Ferrantino, 1993, “The Effects of Intellectual Property Rights on International Trade and Investment”, Weltwirtschaftliches Archiv, Vol.129, 300-331.

Gould David M. and William C. Gruben, 1996, “The role of Intellectual Property Rights in Economic Growth”, Journal of Development Economics, Vol.48, 323-350.

Grossman Gene M. and Elhanan Helpman, 1991, “Endogenous Product Cycles”, The Economic Journal, Vol.101. 1214-1229.

Helpman Elhanan, 1993, "Innovation, Imitation, and Intellectual Property Rights”, Econometrica, Vol.61, No.6, 1247-1280.

Kondo Edson K., 1995, “The Effects of Patent Protection on Foreign Direct Investment”, Journal of World Trade, Vol.29, 97-122.

Japanese Patent Office, 2000, "A Report on the Situation of Infringement on 
Japanese Trademark, Design and Patent, year 2000."

Lai Edwin L.-C, 1998, "International Intellectual Property Rights Protection and the rate of Product innovation”, Journal of Development Economics, Vol.55, 133-153.

Lee and Mansfield, 1996, "Intellectual Property Protection and U.S. Foreign Direct Investment”, The Review of Economics and Statistics, Vol. LXXVIII, 181-186.

Maskus Keith E. and Mohan Penubarti, 1995, "How Trade-Related are Intellectual Property Rights?” Journal of International Economics, Vol. 39, 227-248.

Maskus Keith E., 2000, "Intellecutal Property Rights in the Global Economy", Institute for International Economics.

Rapp Richard T. and Richard P. Rozek, 1990, "Benefits and Costs of Intellectual Property Protection in Developing Countries”, Journal of World Trade, Vol. 24, 75-102

Reichman, J.H. 1995, “Universal Minimum Standards of Intellectual Property Protection under the TRIPS Component of the WTO Agreement”, the International Lawyer, Summer, Vol.29, No.2, 345-388.

Seyoum, 1996, “The Impact of Intellectual Property Rights on Foreign Direct Investment”, The Columbia Journal of World Business, Spring, 50-59.

Vishwasrao Sharmila, 1994, "Intellectual Property Rights and the Mode of Technology Transfer”, Journal of Development Economics, Vol.44, 381-402.

Wooldridge Jeffrey, 2002, Econometric Analysis of Cross Section and Panel Data, Second printing, The MIT Press, Cambridge Massachusetts. 
Table 1. Data from our questionnaire

\begin{tabular}{cccccccccc}
\hline No & CITY & OBSER & IMI & IPRL & PATR & COMP1 & COMP2 & COMP3 & PROF \\
\hline \hline 1 & PK & 21 & 0.3333 & 3.0526 & 0.8571 & 0.6667 & 0.4762 & 0.7143 & 0.4762 \\
2 & SH & 75 & 0.2162 & 2.7246 & 0.6164 & 0.5333 & 0.2933 & 0.7200 & 0.4189 \\
3 & GZ & 11 & 0.5455 & 2.7778 & 0.6364 & 0.7273 & 0.5455 & 0.8182 & 0.5455 \\
4 & SHZ & 9 & 0.0952 & 2.7500 & 0.5556 & 0.3333 & 0.2222 & 0.6667 & 0.3333 \\
5 & ZH & 6 & 0.0000 & 2.6667 & 0.1667 & 0.1667 & 0.6667 & 0.8333 & 0.5000 \\
6 & DG & 3 & 0.6667 & 2.0000 & 0.6667 & 0.6667 & 0.3333 & 0.6667 & 0.3333 \\
7 & SZ & 13 & 0.2500 & 3.0833 & 0.6154 & 0.5385 & 0.6923 & 0.9231 & 0.6154 \\
8 & TJ & 19 & 0.2105 & 3.0000 & 0.7222 & 0.3684 & 0.3158 & 0.5263 & 0.6111 \\
9 & XM & 1 & 0.0000 & 2.0000 & 1.0000 & 1.0000 & 0.0000 & 0.0000 & 0.0000 \\
10 & FZ & 4 & 0.5000 & 2.0000 & 0.6667 & 0.5000 & 0.2500 & 0.5000 & 0.7500 \\
11 & QD & 6 & 0.0000 & 3.2500 & 0.1429 & 0.5000 & 0.5000 & 0.8333 & 0.5000 \\
12 & DL & 18 & 0.3333 & 2.5300 & 0.4706 & 0.3889 & 0.4444 & 0.7778 & 0.5556 \\
13 & SHY & 2 & 0.5000 & 2.0000 & 1.0000 & 1.0000 & 0.0000 & 1.0000 & 0.5000 \\
\hline & Sum & 188 & & & & & & 0.6907 & 0.4723 \\
\hline & Average & & 0.2808 & 2.6027 & 0.6244 & 0.5684 & 0.3646 & 0.690 \\
\hline
\end{tabular}

PK: Peking; SH: Shanghai; GZ: Guangzhou; SHZ: Shenzhen; ZH: Zhuhai; DG: Dongguan;

SZ: Suzhou; TJ: Tenjin; XM: Xiamen; FZ: Fuzhou; QD: Qindao; DL: Dalian; SHY: Shengyang. 
Table 2. List of the meaning of each item in Table 1

IMI

The ratio of the number of subsidiaries in a certain location answered that their products have been experienced been imitated by local firms to the total number of subsidiaries in this location.

IPRL

The average points of the IPRs condition in a certain location marked by every subsidiaries in this location with a scale of 5 .

PATR The ratio of the number of subsidiaries in a certain location answered that their products have been patented or trademark registered to the total number of subsidiaries in this location.

COMP1 The ratio of the number of subsidiaries in a certain location answered that the same products have been imported to China from Japan to the total number of subsidiaries in this location.

COMP2 The ratio of the number of subsidiaries in a certain location answered that the same products have been imported to China from other countries to the total number of subsidiaries in this location.

COMP3 The ratio of the number of subsidiaries in a certain location answered that the same products have been produced by local firms to the total number of subsidiaries in this location.

PROF The ratio of the number of subsidiaries in a certain location answered that their expected profits have not been achieved to the total number of subsidiaries in this location. 
Table 3. Correlation matrix of all items in Table 1

\begin{tabular}{cccccccc}
\hline & IMI & IPRL & PATR & COMP1 & COMP2 & COMP3 & PROF \\
\hline IMI & 1 & & & & & & \\
IPRL & -0.4361 & 1 & & & & & \\
PATR & 0.39904 & -0.4875 & 1 & & & & \\
COMP1 & 0.34551 & -0.4859 & 0.77185 & 1 & & & \\
COMP2 & -0.0939 & 0.67691 & -0.6767 & -0.5899 & 1 & & \\
COMP3 & 0.26237 & 0.38488 & -0.3928 & -0.249 & 0.51807 & 1 & \\
PROF & 0.34707 & 0.30861 & -0.3087 & -0.4465 & 0.48307 & 0.587928 & 1 \\
\hline
\end{tabular}


Table 4. Probit Estimate Results of Equation (3)

\begin{tabular}{|c|c|c|c|c|c|c|c|c|c|c|c|c|}
\hline \multirow{2}{*}{ Variable } & \multicolumn{2}{|c|}{ Subset 1} & \multicolumn{2}{|c|}{ Subset 2} & \multicolumn{2}{|c|}{ Subset 3} & \multicolumn{2}{|c|}{ Subset 4} & \multicolumn{2}{|c|}{ Subset 5} & \multicolumn{2}{|c|}{ Subset 6} \\
\hline & Estimate & t-value & Estimate & t-value & Estimate & t-value & Estimate & t-value & Estimate & t-value & Estimate & t-value \\
\hline Cons. & -1.150 & -5.728 & -1.233 & -5.611 & -1.423 & -5.931 & -1.457 & -4.907 & -1.689 & -5.140 & -2.104 & -3.577 \\
\hline PAT & 0.783 & $3.347^{* * *}$ & 0.672 & $2.734^{* * *}$ & 0.755 & $2.965^{* * *}$ & 0.847 & $3.526^{* * *}$ & 0.761 & $3.078^{* * *}$ & 0.803 & $3.008^{* * *}$ \\
\hline TRAD1 & & & 0.287 & 1.308 & 0.633 & 0.265 & & & & & & \\
\hline TRAD2 & & & & & 0.586 & $2.582^{* *}$ & & & & & & \\
\hline LOCAL & & & & & & & & & 0.353 & 1.443 & 0.419 & $1.403^{*}$ \\
\hline TRAD12 & & & & & & & 0.351 & 1.441 & 0.432 & $1.870^{*}$ & 0.348 & 1.266 \\
\hline $\mathrm{PE}$ & & & & & & & & & & & 0.461 & 0.970 \\
\hline $\mathrm{SH}$ & & & & & & & & & & & 0.261 & 0.627 \\
\hline GU & & & & & & & & & & & 0.731 & 1.608 \\
\hline DA & & & & & & & & & & & 0.736 & 1.470 \\
\hline TEN & & & & & & & & & & & 0.306 & 0.548 \\
\hline XF & & & & & & & & & & & 1.144 & 1.370 \\
\hline SHEN & & & & & & & & & & & 0.515 & 0.526 \\
\hline GLASS & & & & & & & & & & & -0.081 & -0.164 \\
\hline FIBER & & & & & & & & & & & -0.137 & -0.328 \\
\hline VEH & & & & & & & & & & & -0.347 & -0.525 \\
\hline FOOD & & & & & & & & & & & -0.320 & -0.458 \\
\hline $\mathrm{CHE}$ & & & & & & & & & & & 0.013 & 0.038 \\
\hline $\mathrm{MACH}$ & & & & & & & & & & & 0.025 & 0.700 \\
\hline $\bar{R}^{2}$ & \multicolumn{2}{|c|}{0.062} & \multicolumn{2}{|c|}{0.066} & \multicolumn{2}{|c|}{0.098} & \multicolumn{2}{|c|}{0.070} & \multicolumn{2}{|c|}{0.086} & \multicolumn{2}{|c|}{0.141} \\
\hline Observations & \multicolumn{2}{|c|}{179} & \multicolumn{2}{|c|}{177} & \multicolumn{2}{|c|}{177} & \multicolumn{2}{|c|}{179} & \multicolumn{2}{|c|}{179} & \multicolumn{2}{|c|}{178} \\
\hline $\begin{array}{c}\text { Fraction of Correct } \\
\text { Predictions }\end{array}$ & \multicolumn{2}{|c|}{0.726} & \multicolumn{2}{|c|}{0.723} & \multicolumn{2}{|c|}{0.723} & \multicolumn{2}{|c|}{0.726} & \multicolumn{2}{|c|}{0.726} & \multicolumn{2}{|c|}{0.775} \\
\hline
\end{tabular}

*** significant at the level of $1 \%$; ** significant at the level of 5\%; * significant at level the level of $10 \%$. 
Table 5. Probit Estimate Results of Equation (4)

\begin{tabular}{|c|c|c|c|c|c|c|c|c|}
\hline \multirow{2}{*}{ Variable } & \multicolumn{2}{|c|}{ Subset 1} & \multicolumn{2}{|c|}{ Subset 2} & \multicolumn{2}{|c|}{ Subset 3} & \multicolumn{2}{|c|}{ Subset 4} \\
\hline & Estimate & t-value & Estimate & t-value & Estimate & t-value & Estimate & t-value \\
\hline Cons. & 0.032 & 0.197 & -0.104 & -0.581 & -0.277 & -1.085 & 0.383 & 0.462 \\
\hline PAT & 0.047 & 0.232 & -0.015 & -0.071 & -0.061 & -0.283 & -0.131 & -0.555 \\
\hline IMI & -0.250 & -1.150 & -0.334 & -1.489 & -0.342 & -1.532 & -0.385 & -1.631 \\
\hline TRAD1 & & & 0.185 & 0.856 & & & & \\
\hline TRAD2 & & & 0.254 & 1.193 & & & & \\
\hline LOCAL & & & & & 0.101 & 0.464 & 0.370 & 1.381 \\
\hline TRAD12 & & & & & 0.525 & $2.546^{* * *}$ & 0.344 & 1.441 \\
\hline $\mathrm{PE}$ & & & & & & & -0.689 & -0.866 \\
\hline $\mathrm{SH}$ & & & & & & & -0.808 & -1.076 \\
\hline GU & & & & & & & -0.819 & -1.044 \\
\hline DA & & & & & & & -0.489 & -0.599 \\
\hline TEN & & & & & & & -0.357 & -0.433 \\
\hline XF & & & & & & & -0.929 & -0.804 \\
\hline SHEN & & & & & & & -0.929 & -0.804 \\
\hline SU & & & & & & & -0.416 & -0.499 \\
\hline GLASS & & & & & & & -0.662 & -1.414 \\
\hline FIBER & & & & & & & -0.464 & -1.344 \\
\hline VEH & & & & & & & -0.013 & -0.028 \\
\hline FOOD & & & & & & & 1.038 & 1.463 \\
\hline CHE & & & & & & & 0.129 & 0.399 \\
\hline MACH & & & & & & & 0.184 & 0.532 \\
\hline $\bar{R}^{2}$ & \multicolumn{2}{|c|}{0.074} & \multicolumn{2}{|c|}{0.026} & \multicolumn{2}{|c|}{0.045} & \multicolumn{2}{|c|}{0.106} \\
\hline Observations & \multicolumn{2}{|c|}{179} & \multicolumn{2}{|c|}{177} & \multicolumn{2}{|c|}{179} & \multicolumn{2}{|c|}{178} \\
\hline $\begin{array}{l}\text { Fraction of Correct } \\
\text { Predictions }\end{array}$ & \multicolumn{2}{|c|}{0.536} & \multicolumn{2}{|c|}{0.605} & \multicolumn{2}{|c|}{0.603} & \multicolumn{2}{|c|}{0.612} \\
\hline
\end{tabular}

*** Significant at the level of $1 \%,{ }^{* *}$ significant at the level of $5 \%$; * significant at level the level of $10 \%$. 
Table 6. Probit Estimate Results of Equation (4)

\begin{tabular}{|c|c|c|c|c|c|c|c|c|}
\hline \multirow{2}{*}{ Variable } & \multicolumn{2}{|c|}{ Subset 1} & \multicolumn{2}{|c|}{ Subset 2} & \multicolumn{2}{|c|}{ Subset 3} & \multicolumn{2}{|c|}{ Subset 4} \\
\hline & Estimate & t-value & Estimate & t-value & Estimate & t-value & Estimate & t-value \\
\hline Cons. & -0.173 & -1.194 & -0.341 & -1.590 & 0.073 & 0.136 & -0.416 & -0.681 \\
\hline IMI & -0.282 & -1.300 & -0.289 & -1.342 & -0.289 & -1.302 & -0.351 & -1.551 \\
\hline TRAD1 & 0.206 & 1.037 & & & & & & \\
\hline TRAD2 & 0.238 & 1.160 & & & & & & \\
\hline LOCAL & & & 0.109 & 0.527 & & & 0.297 & 1.203 \\
\hline TRAD12 & & & 0.468 & $2.396^{* *}$ & & & 0.288 & 1.275 \\
\hline PE & & & & & 0.101 & 0.168 & 0.116 & 0.191 \\
\hline $\mathrm{SH}$ & & & & & -0.101 & -0.184 & -0.038 & -0.069 \\
\hline GU & & & & & -0.022 & -0.037 & 0.026 & 0.044 \\
\hline DA & & & & & 0.229 & 0.374 & 0.286 & 0.465 \\
\hline TEN & & & & & 0.275 & 0.437 & 0.366 & 0.580 \\
\hline XF & & & & & 0.065 & 0.081 & 0.197 & 0.242 \\
\hline SHEN & & & & & 0.032 & 0.032 & -0.111 & -0.108 \\
\hline SU & & & & & 0.510 & 0.790 & 0.436 & 0.672 \\
\hline GLASS & & & & & -0.824 & $-1.900^{*}$ & -0.680 & -1.474 \\
\hline FIBER & & & & & -0.546 & $-1.750^{*}$ & -0.427 & -1.304 \\
\hline VEH & & & & & -0.235 & -0.551 & -0.004 & -0.008 \\
\hline FOOD & & & & & 0.391 & 0.667 & 0.567 & 0.940 \\
\hline CHE & & & & & 0.178 & 0.581 & 0.203 & 0.642 \\
\hline MACH & & & & & -0.098 & -0.320 & 0.032 & 0.098 \\
\hline $\bar{R}^{2}$ & \multicolumn{2}{|c|}{0.023} & \multicolumn{2}{|c|}{0.036} & \multicolumn{2}{|c|}{0.064} & \multicolumn{2}{|c|}{0.079} \\
\hline Observations & \multicolumn{2}{|c|}{185} & \multicolumn{2}{|c|}{187} & \multicolumn{2}{|c|}{186} & \multicolumn{2}{|c|}{186} \\
\hline $\begin{array}{c}\text { Fraction of Correct } \\
\text { Predictions }\end{array}$ & \multicolumn{2}{|c|}{0.595} & \multicolumn{2}{|c|}{0.594} & \multicolumn{2}{|c|}{0.591} & \multicolumn{2}{|c|}{0.597} \\
\hline
\end{tabular}

** Significant at the level of $5 \%$; * significant at level the level of $10 \%$. 